\title{
Atoms and Nanoparticles of Transition Metals as Catalysts for Hydrogen Desorption from Magnesium Hydride
}

\author{
N. Bazzanella, R. Checchetto, and A. Miotello \\ Dipartimento di Fisica Università degli Studi di Trento, 38123 Povo, Italy \\ Correspondence should be addressed to A. Miotello, antonio.miotello@unitn.it
}

Received 9 April 2010; Accepted 18 August 2010

Academic Editor: Bo Zou

Copyright () 2011 N. Bazzanella et al. This is an open access article distributed under the Creative Commons Attribution License, which permits unrestricted use, distribution, and reproduction in any medium, provided the original work is properly cited.

The hydrogen desorption kinetics of composite materials made of magnesium hydride with transition metal additives (TM: Nb, Fe, and $\mathrm{Zr}$ ) was studied by several experimental techniques showing that (i) a few TM at.\% concentrations catalyse the $\mathrm{H}_{2}$ desorption process, (ii) the $\mathrm{H}_{2}$ desorption kinetics results stabilized after a few $\mathrm{H}_{2}$ sorption cycles when TM atoms aggregate by forming nanoclusters; (iii) the catalytic process occurs also at TM concentration as low as 0.06 at.\% when TM atoms clustering is negligible, and (iv) mixed $\mathrm{Fe}$ and $\mathrm{Zr}$ additives produce faster $\mathrm{H}_{2}$ desorption kinetics than single additive. The improved $\mathrm{H}_{2}$ desorption kinetics of the composite materials can be explained by assuming that the interfaces between the $\mathrm{MgH}_{2}$ matrix and the TM nanoclusters act as heterogeneous sites for the nucleation of the $\mathrm{Mg}$ phase in the $\mathrm{MgH}_{2}$ matrix and promote the formation of fast diffusion channels for $\mathrm{H}$ migrating atoms.

\section{Introduction}

Because of the high hydrogen storage capacity of $\mathrm{MgH}_{2}$, $\sim 7.6$ wt.\%, low cost, and weight, magnesium is still currently investigated for $\mathrm{H}_{2}$ storage applications. Most research efforts are dedicated to the improvement of the kinetic $\mathrm{H}_{2}$ sorption process that is too slow even at temperatures larger than $500 \mathrm{~K}$. The hydrogen desorption process results from many single steps taking place in series: the nucleation of the $\mathrm{Mg}$ phase in the $\mathrm{MgH}_{2}$ parent phase and the diffusion of hydrogen atoms through transformed $\mathrm{Mg}$ and/or not transformed $\mathrm{MgH}_{2}$ layers to the sample surface where the $\mathrm{H}_{2}$ recombitative desorption occurs. The velocity of these reaction steps could be limited by the surface $\mathrm{Mg}$ oxide layer impeding the $\mathrm{H}_{2}$ surface processes $[1,2]$ or by the presence of a continuous $\mathrm{MgH}_{2}$ layer acting as hydrogen diffusion barrier [3]. On the contrary, the hydrogen absorption and desorption kinetic in $\mathrm{Mg}$ can be improved by microstructural refinements such as the reduction of the $\mathrm{Mg}$ or $\mathrm{MgH}_{2}$ grain size: grain boundaries are, in fact, active nucleation sites for the formation or dissociation of the hydride phase and act as preferential diffusion paths for $\mathrm{H}$ atoms [4].
The major improvements are generally obtained by the use of a proper metal or metal oxide additive. Transition metals or transition metal oxides additives favour the $\mathrm{H}_{2}$ dissociation [5] and can further improve the $\mathrm{H}_{2}$ sorption kinetics in different ways. Nanocomposite materials formed by milling $\mathrm{MgH}_{2}$ and $\mathrm{Nb}$ or $\mathrm{Nb}$ oxide powders are the most studied systems. Time-resolved X-rays synchrotron analysis suggested the transformation during $\mathrm{H}_{2}$ desorption at $573 \mathrm{~K}$ of the $\mathrm{NbH}$ nanocatalyst in the metastable, $\mathrm{H}$ vacancy rich $\mathrm{NbH}_{0.6}$ phases: the catalytic effect was thus explained as an enhanced transfer of $\mathrm{H}$ atoms from the $\mathrm{MgH}_{2}$ matrix to the $\mathrm{Mg}$ surface by $\mathrm{H}$ diffusion through the catalyst layers [6]. Recent studies on the structural analysis of $\mathrm{MgH}_{2}$ samples catalysed by $\mathrm{Nb}$ [7] or $\mathrm{Nb}$ oxides [8] suggest the formation of $\mathrm{Mg}-\mathrm{Nb}$ perovskite phases by reaction of $\mathrm{Nb}_{2} \mathrm{O}_{5}$ and $\mathrm{Mg}$ : the perovskite was suggested to act as preferential "pathways" for hydrogen diffusion.

We have recently studied the $\mathrm{H}_{2}$ desorption process from $\mathrm{MgH}_{2}$ samples where the metallic additives, single or mixed atomic species, were completely included inside the $\mathrm{MgH}_{2}$ matrix [9-15]. These samples allow to specifically investigate the role of the additives, in the bulk processes, leading to 
the decomposition of $\mathrm{MgH}_{2}$ phase and to the $\mathrm{H}_{2}$ desorption process. In this paper we present a comprehensive review of our experimental results.

In particular, in Section 2 we review the studies on the hydrogen desorption kinetics from pure and $\mathrm{Nb}$-catalysed $\mathrm{MgH}_{2}$, and then we discuss the role of the $\mathrm{Nb}$ additive when it is distributed inside the $\mathrm{MgH}_{2}$ matrix at concentration ranging from $<0.1$ to about 5 at. $\%$.

In Section 3 we will present the results of the experimental analysis dedicated to the structural and chemical-physical characterization of the $\mathrm{Nb}$ additive when dispersed in the $\mathrm{Mg}$ or $\mathrm{MgH}_{2}$ matrix.

In Section 2 we present a study on the comparison between the catalytic effect of different TM additives contained inside the $\mathrm{MgH}_{2}$ matrix at concentration $\sim 5$ at.\%.

Finally, in Section 3, we will present results on a novel route to enhance the hydrogen desorption kinetics from $\mathrm{MgH}_{2}$ by using mixed TM additive.

\section{Hydrogen Desorption Properties of Nb-Doped $\mathrm{MgH}_{2}$ Samples}

Samples of pure $\mathrm{Mg}$ and $\mathrm{Nb}$-doped $\mathrm{Mg}$ with different concentrations of $\mathrm{Nb}$ (see Table 1) were deposited by RF magnetron sputtering in form of films with thickness $\sim 10$ $20 \mu \mathrm{m}$ on $5 \mathrm{~cm}$ diameter polished graphite wafers. The $\mathrm{Nb}$ doping was obtained by putting a few numbers of small $\mathrm{Nb}$ fragments on the surface of $\mathrm{Mg}$ target in such a way that sputtering process involves both $\mathrm{Mg}$ and $\mathrm{Nb}$, that is, a co sputtering procedure was utilized to prepare $\mathrm{Mg}$-doped samples [9]. To prevent the surface oxidation and stimulate the $\mathrm{H}_{2}$ dissociation at the $\mathrm{Mg}$ surface, samples were coated with a $15 \mathrm{~nm}$ thick Pd capping layer without interrupting the vacuum conditions in the deposition chamber. Pd is known to split hydrogen, and splitting is an important step in the hydrogen sorption process though it might be not the ratelimiting step. Indeed, at temperatures larger than $250-300 \mathrm{~K}$, Pd is transparent to hydrogen [16].

The Nb concentration was measured, after deposition, by Energy Dispersion Spectroscopy (EDS) while Secondary Ions Mass Spectroscopy (SIMS) was employed with samples having $\mathrm{Nb}$ concentration lower than 1 at. $\%$ and to verify the uniform distribution of the $\mathrm{Nb}$ catalyst into the $\mathrm{Mg}$ layers [12]. After deposition, $\mathrm{Mg}$ samples peeled off from the substrate and the self-supporting samples were introduced in a Sievert-type apparatus to study the hydrogen absorption and desorption kinetics: details on the sample preparation, activation procedure, and experimental analysis are described elsewhere $[9,17]$.

In Figure 1 we present the hydrogen desorption kinetics from $\mathrm{MgH}_{2}$ at $623 \mathrm{~K}$ in samples having different $\mathrm{Nb}$ concentrations. The figure shows a strong increase of the reaction velocity for all the $\mathrm{Nb}$-doped $\mathrm{Mg}$ : the reaction halftime $\tau_{1 / 2}$, that is the interval time needed to have half of $\mathrm{MgH}_{2}$ transformed to $\mathrm{h}-\mathrm{Mg}$, decreases from $3250 \pm 50 \mathrm{~s}$ for pure $\mathrm{MgH}_{2}$ to $110 \pm 10 \mathrm{~s}$ for the 2-to- 5 at.\% $\mathrm{Nb}$-doped $\mathrm{MgH}_{2}$. Intermediate values of $\tau_{1 / 2}$ are observed at lower $\mathrm{Nb}$ concentrations: $290 \pm 10 \mathrm{~s}$ for 1 at. $\%$ and $2390 \pm 30 \mathrm{~s}$ for

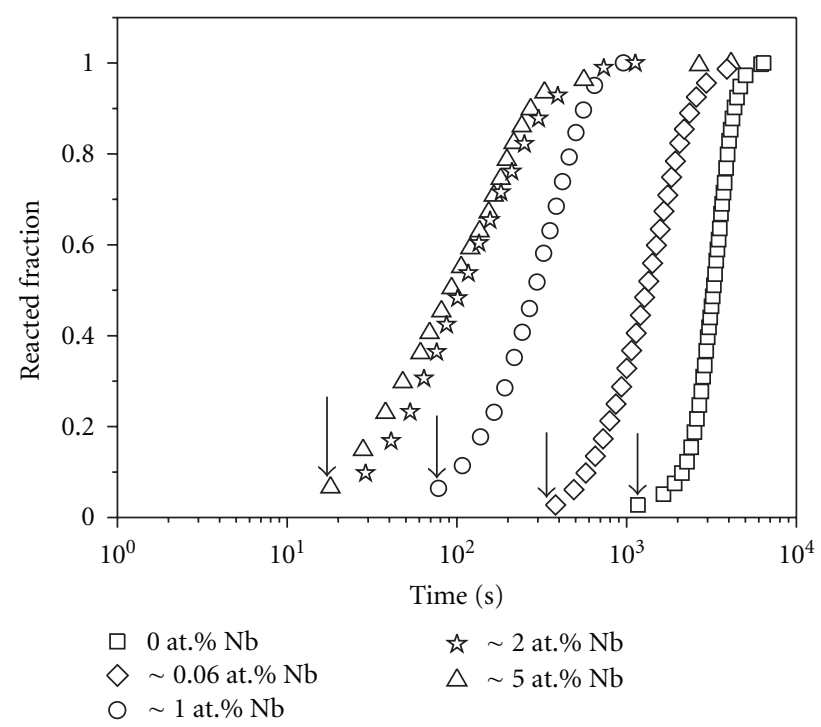

FIgure 1: Hydrogen desorption kinetics at $623 \mathrm{~K}$ from $\mathrm{MgH}_{2}$ samples with different $\mathrm{Nb}$ concentrations.

0.06 at. \%. A corresponding reduction of the incubation time, that is the typical time needed for the nucleation of the $\mathrm{Mg}$ phase, can also be observed in Figure 1 (arrows indicate the reacted fraction firstly evidenced that roughly corresponds to the incubation time).

The desorption processes of Figure 1 have been satisfactorily described in the framework of the JohnsonMehl-Avrami theory for solid-state transformation [18]. The relevant effective parameters of the model, say, the values of the reaction order, $n$, and activation energy, $E_{a}$, are reported in Table 1. The obtained different values suggest that different mechanisms control the $\mathrm{H}_{2}$ desorption kinetics at different $\mathrm{Nb}$ concentrations.

The value $n=4$ obtained for pure $\mathrm{MgH}_{2}$ indicates that the continuous formation of stable $\mathrm{Mg}$ nuclei in the $\mathrm{MgH}_{2}$ parent phase is the rate-limiting step in the $\mathrm{H}_{2}$ desorption kinetics. $n=1$ for $\mathrm{MgH}_{2}$ samples with $\mathrm{Nb}$ content of $2-5$ at.\% indicates an instantaneous nucleation of the $\mathrm{Mg}$ metallic phase in the $\mathrm{MgH}_{2}$ followed by its diffusional growth [9]. The evaluated value of the activation energy, $51 \pm$ $5 \mathrm{~kJ} / \mathrm{mol} \mathrm{H}$, suggests that the diffusional growth is limited by $\mathrm{H}$ atomic diffusion in $\mathrm{Mg}$ layers: this value is, in fact, close to that of the activation energy for $\mathrm{H}$ diffusion in bulk $\mathrm{Mg}, 40 \mathrm{~kJ} / \mathrm{mol} \mathrm{H}$ [19]. Structural analysis by X-Ray Diffraction (XRD) and Extended X-ray Absorption Fine Structure (EXAFS) [12] evidenced, as we will report below, the formation of $\mathrm{Nb}: \mathrm{H}$ nanoclusters. We thus explained the kinetic results by assuming that (a) the interface between the $\mathrm{Nb}: \mathrm{H}$ nanoclusters and the $\mathrm{MgH}_{2}$ matrix offers sites where the instantaneous nucleation of the Mg phase occurs (heterogeneous nucleation) and (b) $\mathrm{H}$ atoms dissociated from the $\mathrm{Mg}$ hydride migrate to the sample surface (where desorption occurs) through domains of transformed Mg. Kinetic data presented in Figure 1 indicate that the same behaviour is shown by samples with $\mathrm{Nb}$ dopant concentration $\geq 2$ at.\%. This result is relevant for application because it shows that 
TABLE 1: Evaluated values of the half-reaction time $\left(\tau_{1 / 2}\right)$ at $T=623 \mathrm{~K}$, order of reaction $(n)$, and activation energy $\left(E_{a}\right)$ of $\mathrm{MgH}_{2}$ samples with different $\mathrm{Nb}$ concentrations.

\begin{tabular}{lccc}
\hline Sample & $\tau_{1 / 2}(\mathrm{~s})$ & $n$ & $E_{a}\left(\mathrm{~kJ} \mathrm{~mol} \mathrm{~m}^{-1} \mathrm{H}\right)$ \\
\hline Pure Mg & $3250 \pm 50$ & 4 & $141 \pm 5$ \\
$\mathrm{Mg}+0.06$ at.\% Nb & $2390 \pm 30$ & 2 & $140 \pm 5$ \\
$\mathrm{Mg}+1$ at. $\% \mathrm{Nb}$ & $290 \pm 10$ & 1.5 & $78 \pm 5$ \\
$\mathrm{Mg}+2 \div 5$ at.\% Nb & $110 \pm 10$ & 1 & $51 \pm 5$ \\
\hline
\end{tabular}

the optimum catalyst concentration can be lower than 5 at.\%, the concentration usually reported for ball-milled $\mathrm{Mg}$ [20]. Note that only a few other catalysts were tested at so low concentration [21].

Relevant differences on hydrogen desorption kinetics are observed in samples with $\mathrm{Nb}$ concentration lower than 25 at.\%: the kinetic curve for 1 at. $\% \mathrm{Nb}$ concentration is reproduced with $n=1.5$ and $E_{a}=78 \pm 5 \mathrm{~kJ} / \mathrm{mol} \mathrm{H}$. The XRD spectrum of such sample (see [12]) shows that $\mathrm{Nb}$ atoms form $\mathrm{Nb}: \mathrm{H})$ nanoclusters with size nearly equal to that observed in samples with larger $\mathrm{Nb}$ content. Because of the lower $\mathrm{Nb}$ concentration, there is thus a larger distance between the $\mathrm{Nb}: \mathrm{H}$ nanoclusters and a lower specific $\mathrm{MgH}_{2}$ $\mathrm{Nb}: \mathrm{H}$ interface area as compared to the 2-5 at.\% Nb-doped samples. The larger value of the activation energy (78 versus $51 \mathrm{~kJ} / \mathrm{mol}$ ) cannot be simply explained as an effective value describing the $\mathrm{H}_{2}$ effusion kinetics of a material that consists of a fraction of $\mathrm{Nb}$-catalysed $\mathrm{MgH}_{2}$ and a fraction of pure $\mathrm{MgH}_{2}$ : effusion simulation carried out by assuming that the hydride consists of a larger fraction of $\mathrm{MgH}_{2}$ with embedded $\mathrm{Nb}$ clusters, and a lower fraction of pure $\mathrm{MgH}_{2}$ cannot reproduce the observed $\mathrm{H}_{2}$ desorption kinetics. On the contrary, by assuming that the observed kinetics still obeys a diffusion-controlled kinetics, the evaluated values of $n=1.5$ and $E_{a}=78 \mathrm{~kJ} / \mathrm{mol}$ can be explained by observing that:

(a) the presence of $\mathrm{Nb}: \mathrm{H}$ clusters still provide a large density of $\mathrm{Mg}$ phase nucleation centers with low activation energy barriers (as in the case of 5 at. $\%$ $\mathrm{Nb}$ ); this point is confirmed by the reduced values of the incubation time when compared with the pure Mg hydride;

(b) the increased distance between the Nb clusters in the $\mathrm{MgH}_{2}$ matrix limits the onset of interconnected $\mathrm{Mg}$ domains which favour the $\mathrm{H}$ atomic diffusion [9].

The evaluated value of the activation energy, $78 \pm 5 \mathrm{~kJ} / \mathrm{mol}$ $\mathrm{H}$, is not much different from the value of the activation energy, $100 \pm 10 \mathrm{~kJ} / \mathrm{mol} \mathrm{H}$, for $\mathrm{H}$ diffusion in $\mathrm{MgH}_{2}$ as reported by Fernández et al. [22]. This suggests that the ratelimiting step in the $\mathrm{H}$ diffusion is given by the energy barrier to be overcome by the migrating species in not transformed $\mathrm{MgH}_{2}$ phase.

A final interesting result comes out from the analysis of the sample with the lower $\mathrm{Nb}$ concentration, 0.06 at.\%. Here the clustering of the $\mathrm{Nb}$ atoms is a negligible process because the $\mathrm{Nb}$ concentration is close to the solubility limit of $\mathrm{Nb}$ in $\mathrm{Mg},[\mathrm{Nb} / \mathrm{Mg}] \sim 10^{-4}$ [23]. A catalytic effect of $\mathrm{Nb}$ on hydrogen desorption can be still observed as indicated by the reduction of the $\tau_{1 / 2}$ parameter with respect to that observed in the undoped $\mathrm{MgH}_{2}$. After repeated $\mathrm{H}_{2}$ absorption-desorption cycles, the catalytic properties decrease and the 0.06 at.\% $\mathrm{Nb}-\mathrm{MgH}_{2}$ exhibits a value of the $\tau_{1 / 2}$ parameter comparable to that of pure $\mathrm{MgH}_{2}$ but lower incubation time. This means that the $\mathrm{Mg}$ nucleation process still results in acceleration. Because the relevant activation energy value of the desorption process is just the same as in the case of pure $\mathrm{Mg}$ (see Table 1), we may conclude that single $\mathrm{Nb}$ atoms may constitute seeds for heterogeneous $\mathrm{Mg}$ nucleation in the same way as homogeneous seeds operate in pure Mg.

In particular, we suggest that the atomic environment around the $\mathrm{Nb}$ impurity atom acts as nucleation seed for the $\mathrm{Mg}$ phase given the presence of local elastic strains due to the atomic size difference between solute $(\mathrm{Nb})$ and solvent atoms $(\mathrm{Mg}, \mathrm{H})$. The decrease of the phase transition velocity after the first absorption-desorption cycles is explained by impurity segregation at extended defects, such as grain boundaries, that reduce the availability of heterogeneous nucleation seeds.

In conclusion, several different mechanisms influence the hydrogen kinetics in $\mathrm{MgH}_{2}$ depending on the $\mathrm{Nb}$ atomic concentration: specifically, at concentration larger than 1 at.\%, $\mathrm{Nb}$ forms nanoclusters that affect both the $\mathrm{Mg}$ nucleation process and hydrogen diffusion. At very low concentration, 0.06 at.\%., $\mathrm{Nb}$ remains atomically dispersed (clustering of the $\mathrm{Nb}$ atoms should be negligible because the $\mathrm{Nb}$ concentration, as indicated above, is close to the solubility limit in $\mathrm{Mg}$ ) and the only effect of $\mathrm{Nb}$ is on favouring the $\mathrm{Mg}$ phase nucleation.

\section{EXAFS and TEM Analysis of Nb-Doped $\mathrm{MgH}_{2}$}

In order to further clarify the role of the $\mathrm{Nb}$ doping element, we studied the evolution of the chemical-physical state of the $\mathrm{Nb}$ atoms dispersed in the $\mathrm{Mg}$ matrix upon hydrogen absorption and desorption cycles. The analyses were carried out by EXAFS, XRD, and Transmission Electron Microscopy (TEM) analysis on three representative $\mathrm{Nb}$ doped Mg samples: (i) as-deposited sample, (ii) activated $\mathrm{MgH}_{2}$ samples after partial $\mathrm{MgH}_{2}$ to $\mathrm{Mg}$ phase transition (hereafter, hydrogenated sample), and (iii) activated sample after complete $\mathrm{MgH}_{2}$ to $\mathrm{Mg}$ phase transition (hereafter, dehydrogenated sample). Details on the measurements and data analysis are reported in [11].

Results show that stable catalytic effects of $\mathrm{Nb}$ are connected with the formation of $\mathrm{Nb}$ nanoclusters dispersed 


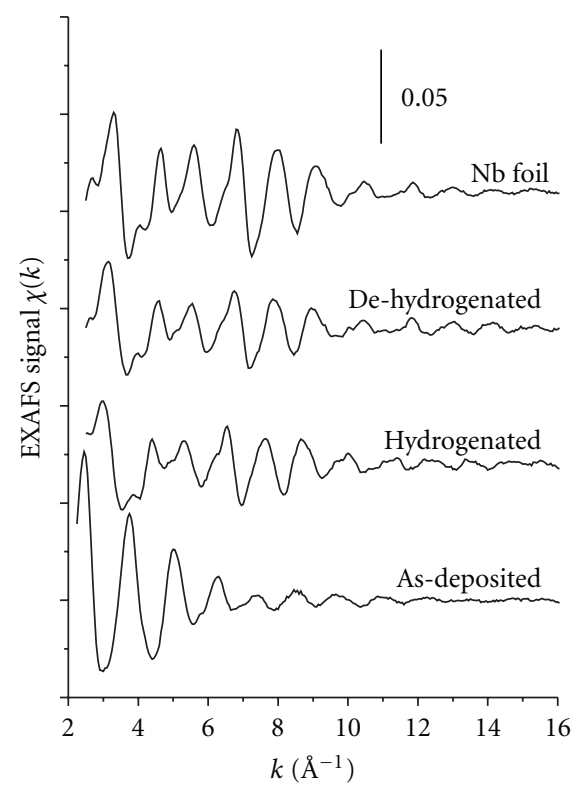

Figure 2: Nb $K$-edge EXAFS spectra from Nb-doped (5at.\%) Mg samples; the spectra of the hydrogenated and dehydrogenated samples are pertinent to fully activated samples.

in the $\mathrm{Mg}$ matrix while no evidence of $\mathrm{Nb}$ oxidation could be deduced from previous analysis.

In Figure 2 we present the EXAFS spectra of the samples together with the spectrum of crystalline $\mathrm{Nb}$ : we observe that the spectrum of the as-deposited sample is different from the spectra of the hydrogenated and dehydrogenated samples which are similar to that of crystalline $\mathrm{Nb}$.

In Figure 3 we show the moduli of the Fourier transformed spectra compared with the corresponding best-fit curves of the first two interatomic correlation signals: the spectrum of the as-deposited sample differs from that of the metallic $\mathrm{Nb}$; the other two are quite similar, except for the fact that for the hydrogenated sample the peaks located at about 2.7 and $3.1 \AA$ are shifted towards higher $R$ (the interatomic distance) values with respect to the $\mathrm{Nb}$ foil spectrum. The results of the EXAFS analysis are reported in Table 2.

In the as-deposited sample, the average local structure around $\mathrm{Nb}$ is composed mainly of $\mathrm{Mg}$ atoms, at a distance that is shorter with respect to the corresponding value of the crystalline $\mathrm{Mg}$ and appears in agreement with the first $\mathrm{Nb}-\mathrm{Mg}$ coordination distance obtained by simulating an $\mathrm{Nb}$ substitutional impurity in an $\mathrm{Mg}$ cluster. Besides this main signal, the analysis evidenced also an $\mathrm{Nb}-\mathrm{Nb}$ correlation, as shown in Figure 3(b), where in the backtransformed $\mathrm{k}$-space the filtered data and fit are compared and the different contributions to the fit are reported. The $\mathrm{Nb}-\mathrm{Nb}$ correlation indicates the presence of $\mathrm{Nb}$ aggregates: the fact that the coordination number is low (about 1) and the $\mathrm{Nb}-\mathrm{Nb}$ distance is shorter than for the bulk $\mathrm{Nb}$ strongly suggests that the clusters are composed of few $\mathrm{Nb}$ atoms. In the hydrogenated sample, the $\mathrm{Nb}-\mathrm{Mg}$ signal is below the detectable limit; two $\mathrm{Nb}-\mathrm{Nb}$ correlations are evident indicating the presence of $\mathrm{Nb}$-containing nanoclusters: the $\mathrm{Nb}-\mathrm{Nb}$ distances are $\sim 4.5 \%$ longer than the corresponding values in crystalline $\mathrm{Nb}$. We ascribe this fact to the presence of $\mathrm{H}$ atoms into the $\mathrm{Nb}$ clusters increasing the interatomic distance: the local structure around $\mathrm{Nb}$ is in agreement with both the $\alpha \mathrm{Nb}-\mathrm{H}$ phase (with an $\mathrm{H} / \mathrm{Nb}$ atomic ratio of 0.9) [24] and with the orthorhombic $\beta \mathrm{Nb}-\mathrm{H}$ phase (with an $\mathrm{H} / \mathrm{Nb}$ atomic ratio higher than 0.8) [25]. It is worth noting that the coordination number is lower than the corresponding value in the bulk $\mathrm{Nb}$, due to the fraction of $\mathrm{Nb}$ atoms located on the cluster surface and, possibly, to $\mathrm{Nb}$ atoms dispersed in the $\mathrm{Mg}$ matrix. After the hydrogen desorption process, the $\mathrm{Nb}$ is still aggregated in nanoclusters: in this case, the $\mathrm{Nb}-\mathrm{Nb}$ coordination distances are those of the corresponding bulk phase: this indicates the $\mathrm{H}$ desorption from the $\mathrm{Nb}$ clusters (see [6] to gain insight on formation, decomposition, and general features on stability of $\mathrm{NbH}$ ). The fact that the coordination numbers in this case are even lower than those of the hydrogenated sample could likely indicate a smaller size of the nanoclusters and/or a larger fraction of $\mathrm{Nb}$ atoms dispersed into the $\mathrm{Mg}$ matrix. As in the hydrogenated sample, the Nb-Mg signal is below the detectable limit for the EXAFS spectroscopy.

The XRD spectrum of the as-deposited sample [9] shows a preferential growth of the $\mathrm{Mg}$ film with the (0001) planes parallel to the substrate. After hydrogenation, the sample shows a complex pattern formed of many peaks; see Figure 4: the peaks can be attributed to a tetragonal $\mathrm{MgH}_{2}$ phase with lattice parameters $a=0.4517 \mathrm{~nm}$ and $c=0.30205 \mathrm{~nm}$ (ICDD card n. 12-697) and to an orthorhombic $\beta-\mathrm{NbH}_{0.89}$ phase with lattice parameters $a=0.484 \mathrm{~nm}, b=0.490 \mathrm{~nm}$, and $c=0.345 \mathrm{~nm}$ (ICDD card n. 7-263). The unindexed peaks are due to $\mathrm{Mg}$ layers that have lost the absorbed hydrogen. The mean grains size of the $\beta-\mathrm{NbH}_{0.89}$ phase, estimated by using the Scherrer equation after deconvolution of the $\mathrm{Mg}(101)$ and $\mathrm{NbH}_{0.89}$ (200) peaks, see the inset of Figure 4, is $\sim 20 \mathrm{~nm}$. The presence of metallic $\mathrm{Nb}$ was never detected in the hydrogenated sample. The dehydrogenated sample shows a very simple XRD pattern where, apart from the unindexed Mg peaks, only the first three peaks of metallic $\mathrm{Nb}$ (bcc, $a=$ 0.33066 nm, ICDD card n. 35-789) are present; see Figure 5. The mean grains size of the metallic $\mathrm{Nb}$, calculated from the measurement of the FWHM of the $\mathrm{Nb}(110)$ peak, is $\sim 15 \mathrm{~nm}$. It is worth to note that in this case the $\mathrm{Mg}$ - and $\mathrm{Nb}$-hydrides are completely disappeared.

TEM observations performed on the as-deposited sample evidenced the preferential growth of the film, in agreement with the XRD results, as well as the absence of any nanocluster or precipitate inside the $\mathrm{Mg}$ grains. The size of these grains ranges from 0.1 to $1.5 \mu \mathrm{m}$. The electron diffraction pattern has a ring structure attributable to $\mathrm{Mg}$. In this case, the few-atom aggregates detected by the EXAFS spectroscopy are most likely too small to give a significant contribution to the whole diffraction pattern. A completely different appearance is shown by the hydrogenated sample: spherical nanoclusters with dimensions ranging from 5 to $25 \mathrm{~nm}$, not uniformly dispersed inside the grains, are clearly visible after few minutes of permanence under the electron 


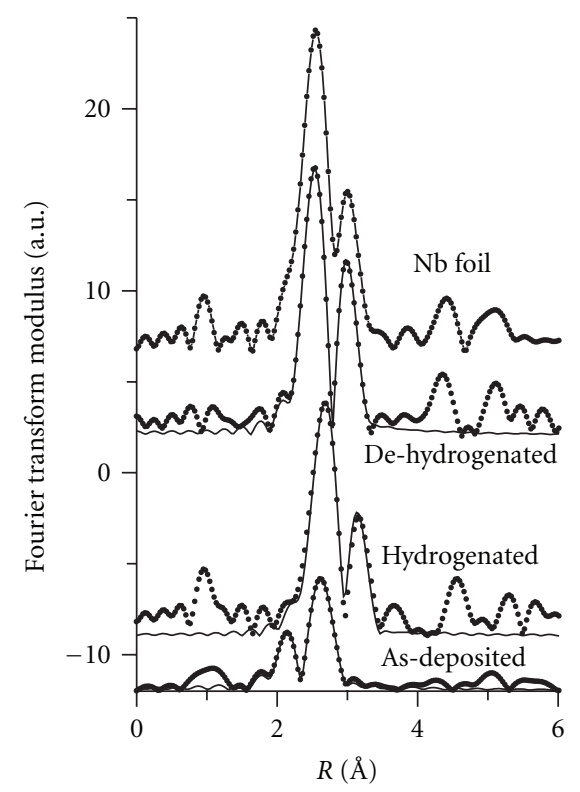

(a)

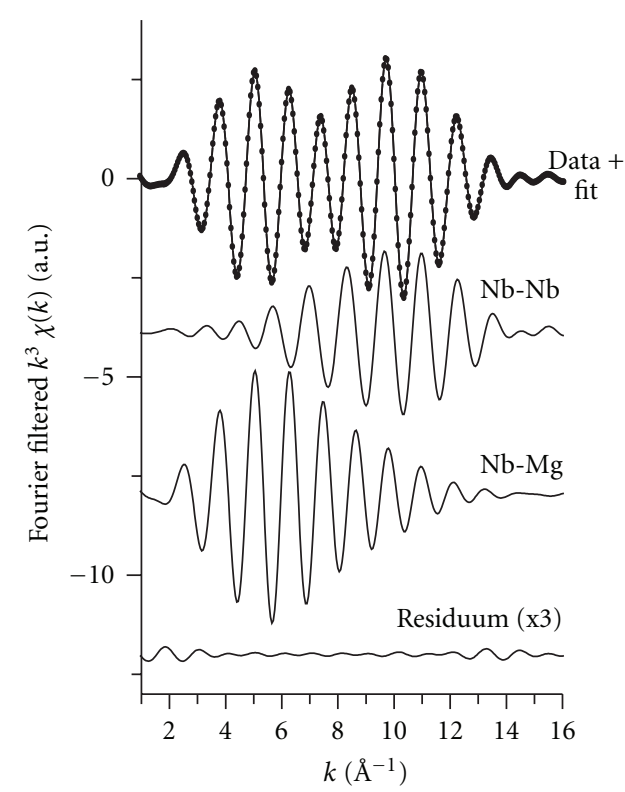

(b)

FIGURE 3: EXAFS analysis of the Nb-doped ( 5 at.\%) Mg samples. (a) $k^{3}$-weighted Fourier transform moduli (transformation range $k=3-13$ $\AA^{-1}$ for the as-deposited sample, $k=3-16 \AA^{-1}$ for the others) of the EXAFS spectra (markers) and corresponding best-fit curves (solid line) of the first two coordination signals ( $\mathrm{Nb}-\mathrm{Mg}$ and $\mathrm{Nb}-\mathrm{Nb}$ for the as-deposited sample, two Nb-Nb for the others); no back-scatterer phaseshift correction was applied in the figure. (b) Fourier filtered spectrum (markers) in the fitting range and superimposed fit (solid line) of the as-deposited EXAFS spectrum; the residuum and the two single-scattering signals that contribute to the fit are reported.

TAble 2: Results of the Nb $K$-edge EXAFS analysis on Nb-doped $\mathrm{Mg}$ films; for each pair of atoms, $N$ is the coordination number, $R$ the interatomic distance, and $\sigma^{2}$ the Debye-Waller factor. The uncertainty in the fitting results corresponds to a confidence level of $68 \%$. Crystallographic data for metallic $\mathrm{Nb}$ and the simulation of the local structure around an $\mathrm{Nb}$ substitutional impurity into the Mg lattice are also reported.

\begin{tabular}{lcccc}
\hline Sample & & $N$ & $R(\AA)$ & $\sigma^{2}\left(10^{-4} \AA^{2}\right)$ \\
\hline \multirow{2}{*}{ As-deposited } & $\mathrm{Nb}-\mathrm{Nb}$ & $1.2 \pm 0.4$ & $2.73 \pm 0.01$ & $38 \pm 9$ \\
& $\mathrm{Nb}-\mathrm{Mg}$ & $9.6 \pm 0.9$ & $3.08 \pm 0.01$ & $3.00 \pm 0.02$ \\
Hydrogenated & $\mathrm{Nb}-\mathrm{Nb}$ & $5.6 \pm 0.3$ & $3.45 \pm 0.02$ & $57 \pm 6$ \\
& $\mathrm{Nb}-\mathrm{Nb}$ & $4.2 \pm 0.2$ & $2.87 \pm 0.01$ & $66 \pm 8$ \\
dehydrogenated & $\mathrm{Nb}-\mathrm{Nb}$ & $4.0 \pm 0.2$ & $3.32 \pm 0.01$ & 2.8638 \\
& $\mathrm{Nb}-\mathrm{Nb}$ & $3.0 \pm 0.2$ & 3.3068 \\
metallic $\mathrm{Nb}$ & $\mathrm{Nb}-\mathrm{Nb}$ & 8 & 3.075 \\
& $\mathrm{Nb}-\mathrm{Nb}$ & 6 & 3.195 \\
\hline
\end{tabular}

beam (a longer permanence induces the decomposition of the Mg- and Nb-hydrides). The electron diffraction pattern of the sample only shows the presence of $\mathrm{Mg}$ rings and a very weak ring attributable to metallic $\mathrm{Nb}$. Finally, the dehydrogenated sample is stable under the electron beam, and its structure is formed of spherical nanoclusters with dimensions in the range $10-20 \mathrm{~nm}$. These nanoclusters are not uniformly distributed inside the grains; see Figure 6, where the $\mathrm{Nb}$ particles appear as small black dots. The electron diffraction pattern of this sample is formed of spotty rings due to $\mathrm{Mg}$ and few well evident extra spots due to metallic $\mathrm{Nb}$.
The present structural analysis thus shows that the accelerated $\mathrm{H}_{2}$ desorption kinetics is connected to the presence of the $\mathrm{Nb}$ nanoclusters [12]. As suggested by the analysis of the desorption curves, the role of the nanoclusters is connected to the accelerated nucleation of the $\mathrm{Mg}$ phase in the $\mathrm{MgH}_{2}$ matrix: the interface between the $\mathrm{Nb}: \mathrm{H}$ nanoclusters and the $\mathrm{MgH}_{2}$ matrix favours the instantaneous nucleation of the $\mathrm{Mg}$ phase (heterogeneous nucleation). An embryo of the $\mathrm{Mg}$ phase can reduce its energetic formation cost at the $\mathrm{MgH}_{2}-\mathrm{Nb}: \mathrm{H}$ interface as discussed in general framework; see $[26,27]$. In addition, the $\mathrm{MgH}_{2}-\mathrm{Nb}: \mathrm{H}$ interface can favour the $\mathrm{Mg}$ phase growth. Indeed, in diffusional phase 


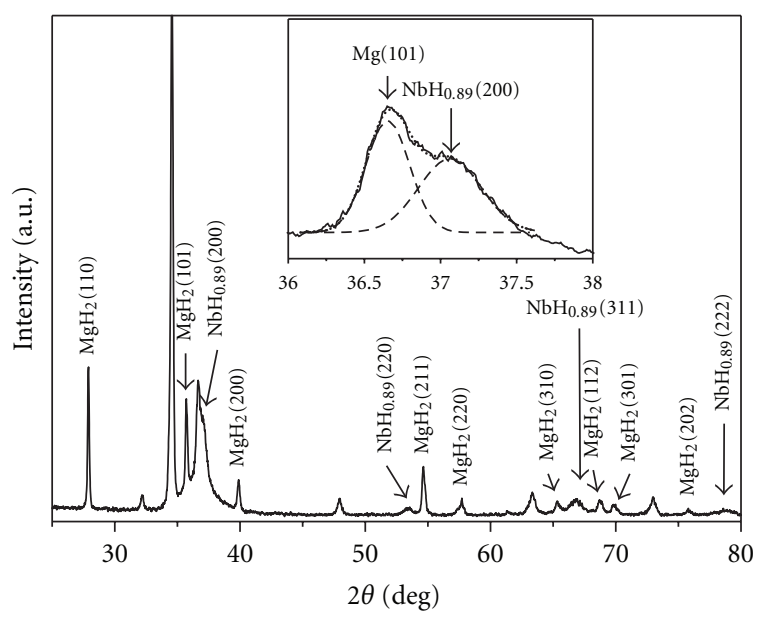

FIGURE 4: XRD spectrum of the 5 at.\% $\mathrm{Nb}$-doped $\mathrm{MgH}_{2}$ sample, partially dehydrogenated. The inset shows the deconvolution of the $\mathrm{Mg}$ (101) and $\mathrm{NbH}_{0.89}$ (200) peaks: continuous line: experimental data, dashed line: fitting, and dotted line: envelope of the fitted curves.

transitions where transport of the atomic components occurs over paths longer than the interatomic distance, new phases are often observed to nucleate at grain boundaries of the parent phase. These extended defects result in fast diffusion channels for migrating atoms thus giving rise, in the lattice layers around them, to the critical solute concentration for the phase transition [26, 27]. In the present $\mathrm{Nb}$-doped $\mathrm{MgH}_{2}$ samples, the $\mathrm{MgH}_{2}-\mathrm{Nb}: \mathrm{H}$ interface can play a similar role allowing an effective removal of the $\mathrm{H}$ atoms dissociated from adjacent $\mathrm{MgH}_{2}$ layers and thus favouring the formation of Mg nuclei having critical size.

\section{Comparison between Desorption Kinetics of $\mathrm{Nb}-, \mathrm{Zr}^{-}$, and Fe-Doped $\mathrm{MgH}_{2}$}

In this section we present a comparative study on the $\mathrm{H}_{2}$ desorption from the $\mathrm{MgH}_{2}$ matrix doped with different metallic elements dispersed in atomic concentration, say, 25 at.\% [13]. Results on $\mathrm{Nb}$ were reported above and now we consider, for comparison, $\mathrm{Fe}$ and $\mathrm{Zr}$ because (i) they are transition metals (TM) with catalytic properties for the $\mathrm{H}_{2}$ sorption kinetics in $\mathrm{Mg}$ and (ii) they do not form binary phases with $\mathrm{Mg}$ and show negligible solubility [23]. Nb, $\mathrm{Zr}$, and Fe have different "affinity" with hydrogen in the temperature range $(400 \mathrm{~K}<T<700 \mathrm{~K})$. $\mathrm{Nb}$ forms interstitial alloys with hydrogen: the $\alpha$ phase is a random interstitial alloy of $\mathrm{H}$ in bcc $\mathrm{Nb}$ with $\mathrm{H} / \mathrm{Nb}$ ratio $<0.31$. $\mathrm{Zr}$ forms stable phase: the $\delta$ phase having fcc structure with $1.31<$ $\mathrm{H} / \mathrm{Nb}<2$. Fe does not form any binary hydride phase and shows negligible $\mathrm{H}$ solubility [28]. In these new composite samples, the atomic \% concentration, as detected by EDS, was $\sim 5$ at. $\%$ for $\mathrm{Fe}$ (the same as for $\mathrm{Nb}$ ) and $\sim 3$ at.\% for $\mathrm{Zr}$ : these concentrations are larger than the maximum solubility of the $\mathrm{TM}$ in $\mathrm{Mg}, 0.00043$ at.\% for $\mathrm{Fe}$ at the eutectoid temperature of $920 \mathrm{~K}$, close to $1.3 \times 10^{-4}$ for $\mathrm{Nb}$ in liquid $\mathrm{Mg}$ at $1500 \mathrm{~K}$, and lower than $0.1 \mathrm{at} . \%$ for $\mathrm{Zr}$ at temperatures

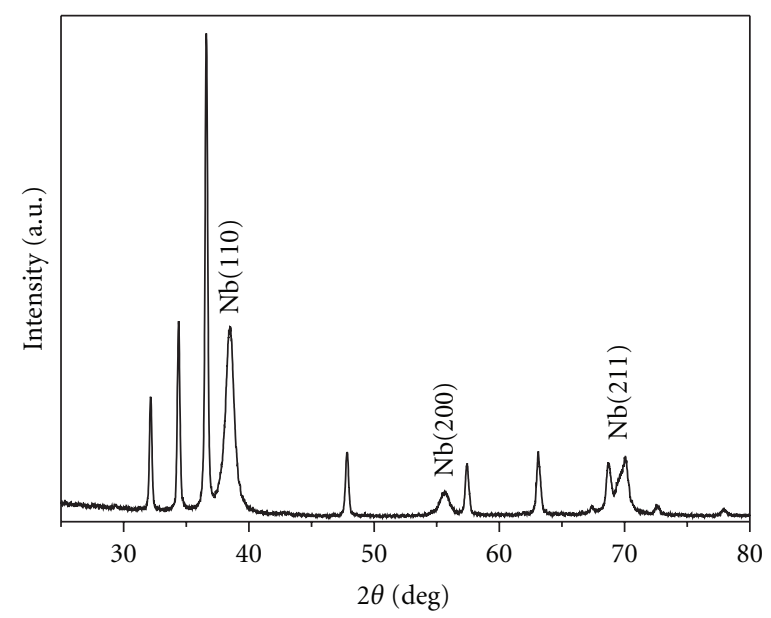

FIGURE 5: XRD spectrum of the dehydrogenated 5 at.\% Nb-doped samples.

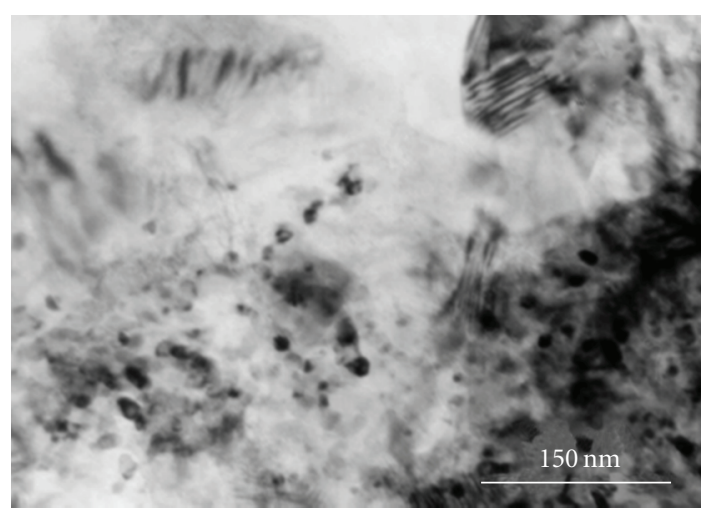

FIGURE 6: TEM micrograph of the dehydrogenated sample showing distribution and size of the metallic $\mathrm{Nb}$ nanoclusters.

lower than $700 \mathrm{~K}$ [23]. These equilibrium properties indicate that precipitation of the metal additive atoms is expected upon the thermal treatment leading to the sample activation at $623 \mathrm{~K}$ and/or during $\mathrm{H}_{2}$ cycling.

The room temperature XRD spectra of the TM-doped samples, partially dehydrogenated, confirm cluster formation. While Fe remains in the metallic state, see Figure 7, $\mathrm{Nb}$ and $\mathrm{Zr}$ form hydride phase as shown by the $\mathrm{NbH}_{0.89}$ and $\mathrm{ZrH}_{1.66}$ reflection peaks in Figures 8 and 9, respectively: no evidence of metallic $\mathrm{Nb}$ or $\mathrm{Zr}$ was found in the partially desorbed samples. The obtained TM-H phases are appropriate to equilibrium phase diagram at room temperature [28]. The Debye-Scherrer analysis of the XRD peak indicates the formation of TM nanoclusters having dimensions in the $10 \div 20 \mathrm{~nm}$ range while $\mathrm{Mg}$ and $\mathrm{MgH}_{2}$ maintain the microcrystalline structure [9-11]. The aggregation of TM atoms to form nanoclusters during cycling in hydrogen is confirmed by the evolution of XRD spectra from asdeposited to fully cycled samples $[9,11]$ and by also comparing with EXAFS analysis [11].

In Figure 10 we present the isothermal $\mathrm{H}_{2}$ desorption curves of the pure and metal-doped $\mathrm{MgH}_{2}$ samples at the 


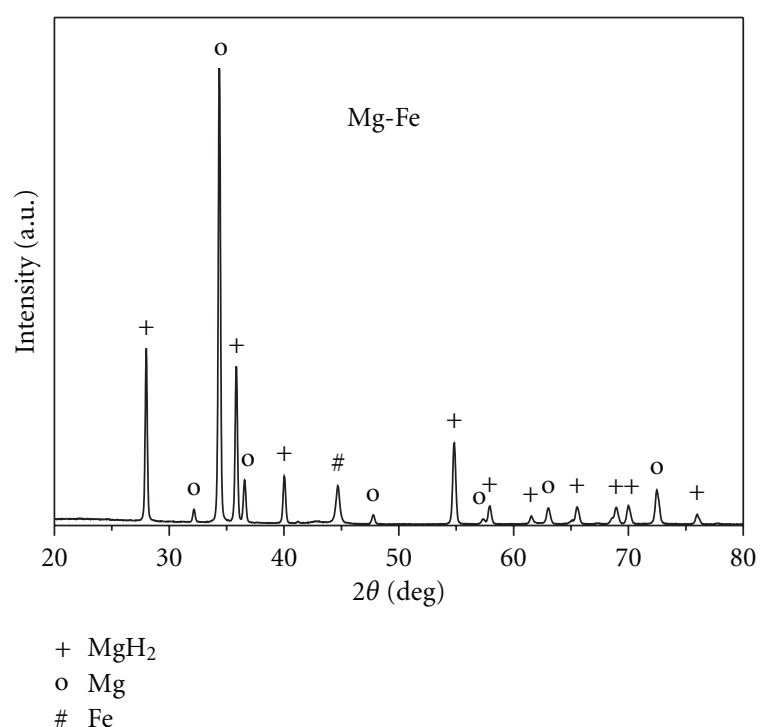

FIgURE 7: Room temperature XRD spectra of the 5 at.\% Fe doped $\mathrm{MgH}_{2}$ samples, partially dehydrogenated after full activation.

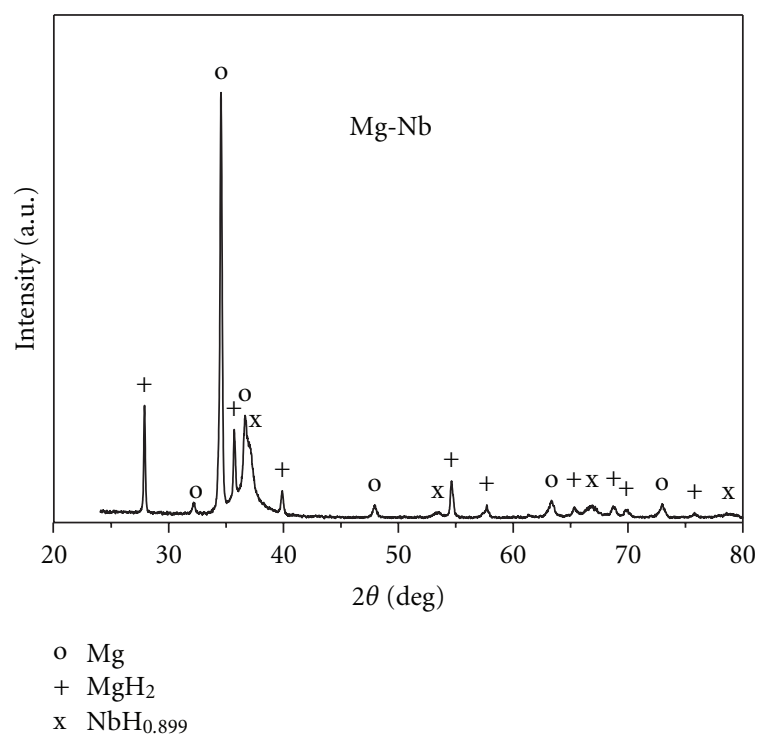

Figure 8: Room temperature XRD spectra of the 5 at.\% Nb-doped $\mathrm{MgH}_{2}$ samples, partially dehydrogenated after full activation.

representative temperature of $623 \mathrm{~K}$. The curves show a strong improvement of the $\mathrm{H}_{2}$ desorption kinetics in the examined TM-doped samples when compared to the pure $\mathrm{MgH}_{2}$ : at this temperature the interval time required for $50 \%$ transformation decreases from $\sim 3000 \mathrm{~s}$ for pure $\mathrm{MgH}_{2}$, to $\sim 200 \mathrm{~s}$ for the $\mathrm{Zr}$-doped sample, and to $\sim 100 \mathrm{~s}$ for $\mathrm{Nb}$ - and Fe-doped samples.

In Figure 11 we present the TDS spectra of the pure and $\mathrm{TM}$-doped $\mathrm{MgD}_{2}$ samples after their complete activation. (For the TDS analysis deuterium was chosen rather than hydrogen to improve the signal-to-noise ratio: at $2 \%$ of the TDS peak height the signal-to-noise ratio of the $m / e=4$ signal was better than $10^{2}$ ).

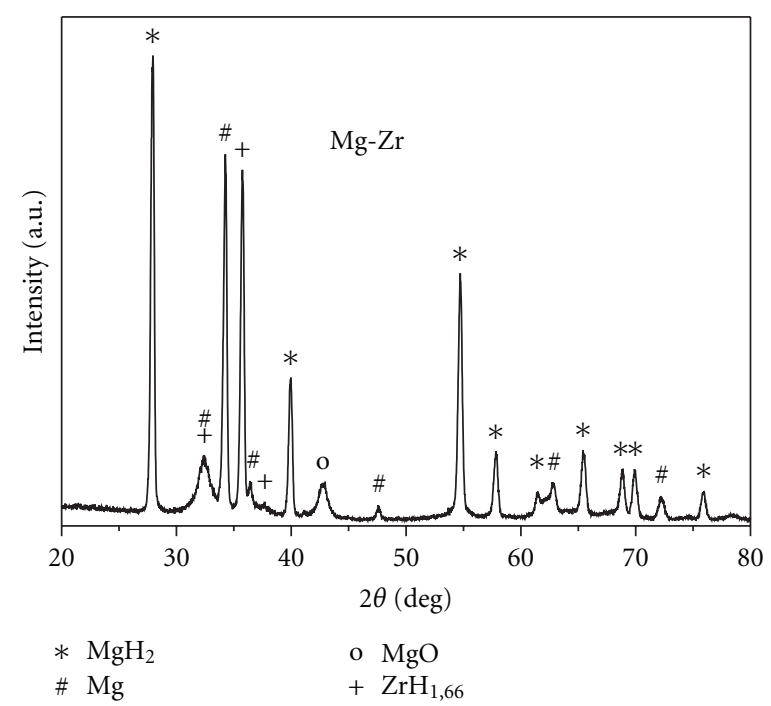

FIgURE 9: Room temperature XRD spectra of the 3 at.\% Zr-doped $\mathrm{MgH}_{2}$ samples, partially dehydrogenated after full activation.

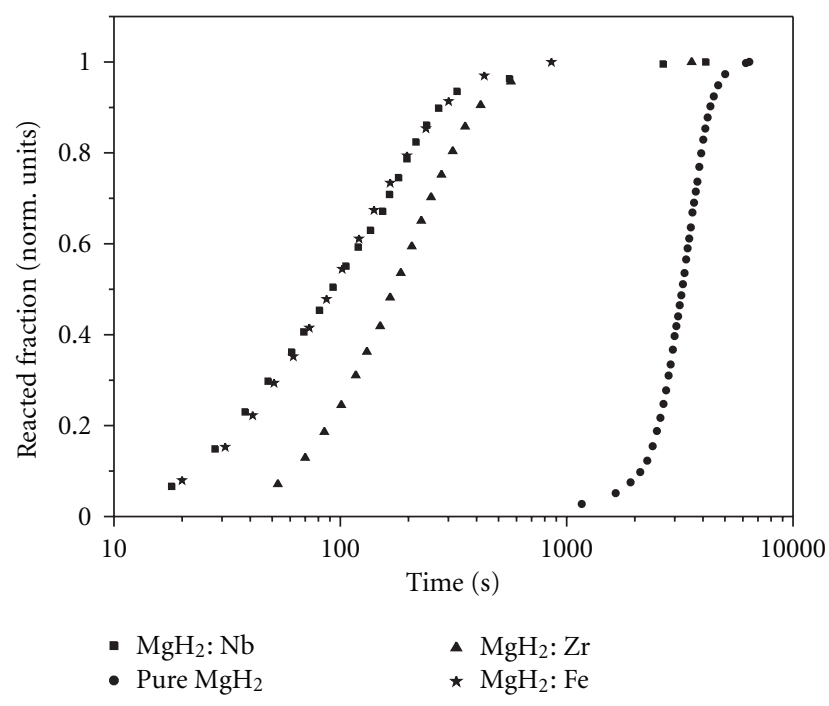

Figure 10: Isothermal $\mathrm{H}_{2}$ desorption curves of the pure and TMdoped $\mathrm{MgH}_{2}$ samples at $623 \mathrm{~K}$, after their fully activation.

The most important information provided by the spectra is the position of the peak temperature $T_{P}$ at which the desorption rate reaches its maximum: this temperature allows a direct comparison of the influence of the TM additive on the thermal stability of the $\mathrm{MgD}_{2}$ phase. The obtained spectra confirm the trend observed in the isothermal curves evidencing lower thermal stability of the TM-doped samples as compared to pure $\mathrm{MgD}_{2}$. The $\mathrm{Fe}$ - and $\mathrm{Nb}$-doped sample show TDS peaks at $\sim 470$ and $\sim 480 \mathrm{~K}$, respectively while the $\mathrm{Zr}$-doped samples shows TDS peak at $\sim 535 \mathrm{~K}$. Pure $\mathrm{MgD}_{2}$ shows the TDS peak at a larger temperature, close to $630 \mathrm{~K}$.

The present $\mathrm{H}_{2}$ (or $\mathrm{D}_{2}$ ) desorption results show that the dispersion of different TM nanoclusters inside the $\mathrm{MgH}_{2}$ matrix accelerates the $\mathrm{H}_{2}$ desorption process and that TM 


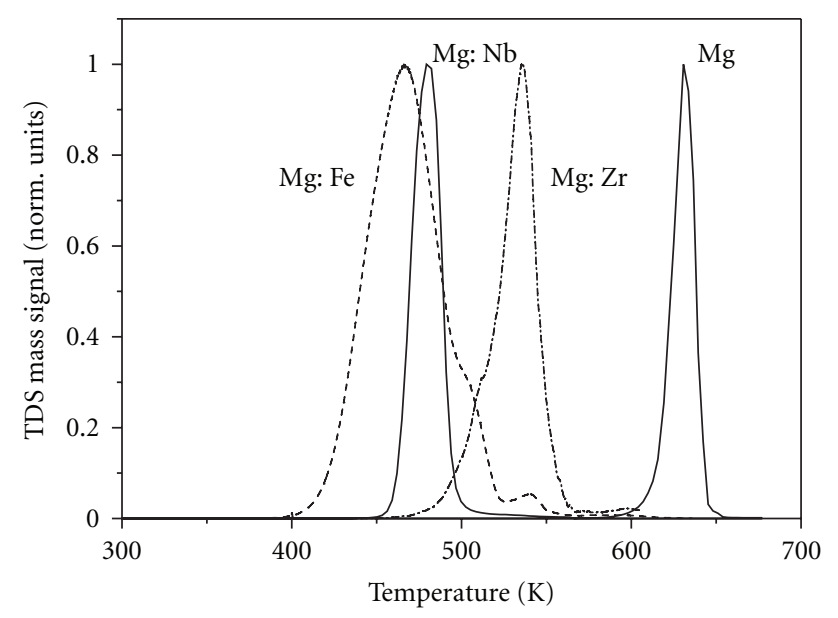

FIGURE 11: TDS spectra of the pure and TM-doped $\mathrm{MgD}_{2}$ samples after their fully activation.

nanoclusters distributed in the $\mathrm{MgH}_{2}$ matrix catalyse the $\mathrm{Mg}$ phase nucleation even if they present different chemical affinity with hydrogen. This point is also confirmed by the strong reduction of the nucleation time (Figure 10) shown by the isothermal desorption curves of the TM doped samples ( $\sim 10 \mathrm{~s}$ for $\mathrm{Nb}$ and $\mathrm{Fe}$ and $\sim 50 \mathrm{~s}$ for $\mathrm{Zr}$ ) as compared to that pertinent to the pure $\mathrm{MgD}_{2}, \sim 1000 \mathrm{~s}$.

In conclusion, composite materials consisting on TMdoped $\mathrm{Mg}$ (TM: $\mathrm{Nb}, \mathrm{Fe}$, and $\mathrm{Zr}$ ) with TM content of a few at.\% concentration show accelerated $\mathrm{H}_{2}$ desorption kinetics when compared to the pure $\mathrm{MgH}_{2}$ samples (the diffusion of migrating hydrogen atoms has been measured by "in situ" EXFAS for the $\mathrm{MgH}_{2} / \mathrm{Nb}_{2} \mathrm{O}_{5}$ system [29]); while in the pure $\mathrm{MgH}_{2}$ the $\mathrm{H}_{2}$ desorption kinetics is controlled by the nucleation and growth of the Mg phase, in TM-doped samples the $\mathrm{H}_{2}$ release is controlled by the $\mathrm{H}$ diffusion through $\mathrm{Mg}$ layers. The improved $\mathrm{H}_{2}$ desorption kinetics can be explained by the presence of extended interfaces between $\mathrm{MgH}_{2}$ and TM nanoclusters acting as heterogeneous sites for the nucleation of the $\mathrm{Mg}$ phase and promoting the formation of fast diffusion channels for $\mathrm{H}$ migrating atoms.

\section{Mixed Zr-Fe Catalysts}

In the previous sections we observed that the presence of TM nanoclusters dispersed in the $\mathrm{MgH}_{2}$ matrix accelerates the $\mathrm{H}$ desorption kinetics. Two additional effects were also evidenced by the experiments [12]. First, in Mg samples with $\mathrm{Nb}$ content in the at.\% level, the hydrogen desorption kinetics, when $\mathrm{Nb}$ does not form precipitates, was faster than that observed in the activated sample where $\mathrm{Nb}$ forms nanoclusters. Second, catalytic effects were also observed when the metallic additive was present at levels lower than 0.1 at.\% in the $\mathrm{Mg}$ matrix, that is, close to the solubility limit of $\mathrm{Nb}$ in $\mathrm{Mg}$. The desorption curves presented the same kinetics (nucleation and growth mechanisms) and activation energy as that of the pure $\mathrm{MgH}_{2}$ samples but a shorter nucleation time: we thus suggested that also $\mathrm{Nb}$ atoms (or few-atom aggregates) dispersed in the $\mathrm{Mg}$ matrix act as

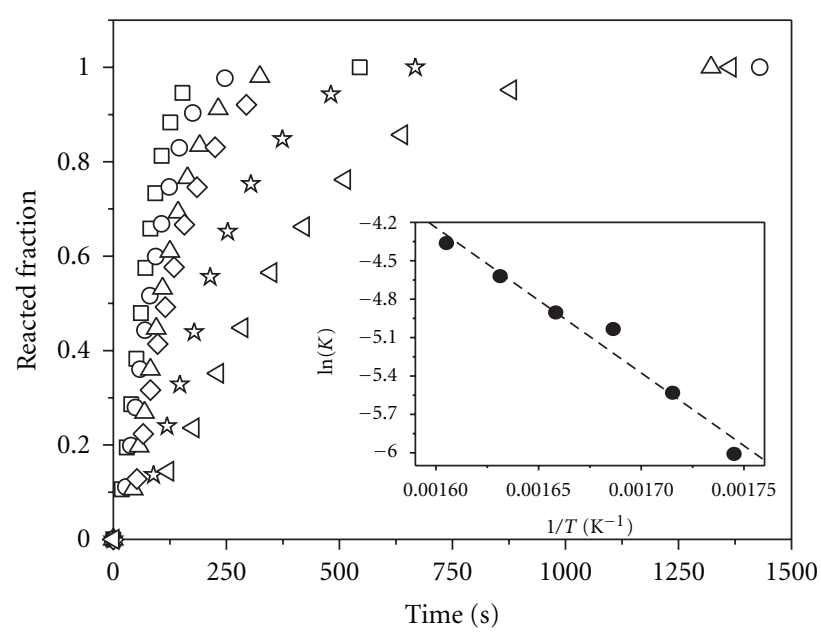

FIGURE 12: Dehydrogenated fraction versus time at various temperatures for the $\mathrm{Mg}$ sample with mixed $\mathrm{Fe}-\mathrm{Zr}$ additives at $\square 623 \mathrm{~K}$, $\mathrm{O} 613 \mathrm{~K}, \triangle 603 \mathrm{~K}, \diamond 593 \mathrm{~K}$, $\star 583 \mathrm{~K}$, and $\triangleleft 573 \mathrm{~K}$. In the insert we present the Arrhenius plot of the desorption rate constant $k$ : the straight line is the least square fit.

nucleation centres for the $\mathrm{Mg}$ phase in the parent $\mathrm{MgH}_{2}$ phase [12].

These results suggest that a route to accelerate the $\mathrm{H}_{2}$ desorption kinetics is to limit the aggregation of the additives in form of large clusters and to favour a better distribution of the catalyst in form of small clusters or few atoms aggregates into the $\mathrm{MgH}_{2}$ matrix. To this purpose we have prepared $\mathrm{MgH}_{2}$ samples with mixed TM additives: in this section we report on the hydrogen desorption from magnesium hydride samples containing $\mathrm{Fe}$ and $\mathrm{Zr}$, at a few at.\% concentration [14].

We have used $\mathrm{Zr}$ and Fe because they have catalytic effects when dispersed in form of nanocluster in the $\mathrm{MgH}_{2}$ matrix and because they do not form binary phases with Mg matrix. Finally $\mathrm{Zr}$ is heavier than $\mathrm{Fe}$ and has larger atomic diameter, 4.32 versus $3.44 \AA$ : they thus have different mobility values and we thus expect different clustering processes when sharing the same host matrix $(\mathrm{Mg})$.

The $\mathrm{Fe}$ atoms will preferentially form clusters thus limiting the aggregation process of $\mathrm{Zr}$ atoms because $\mathrm{Fe}$ atoms can faster reach extended defects in the $\mathrm{Mg}$ (or $\mathrm{MgH}_{2}$ ) matrix which are the typical nucleation centers. To experimentally study this process we prepared $\mathrm{Mg}$ samples with (i) $\mathrm{Fe}$ single additive (5 at.\%), (ii) $\mathrm{Zr}$ single additive (3 at.\%), and (iii) mixed additive with 7 at.\% ( 5 and $\sim 2$ at. $\%$ content for $\mathrm{Fe}$ and $\mathrm{Zr}$, resp.).

XRD analysis of the as-deposited samples showed no evidence of metallic Fe and $\mathrm{Zr}$ : this means that the presence of the additive is in atomic form or in form of a few atoms aggregates as previously observed with $\mathrm{Mg}$ samples containing the $\mathrm{Nb}$ additive [11]. Based on previous XRD analysis of TM-doped $\mathrm{Mg}$, it is really difficult to suppose the presence of metallic amorphous phase. In Figure 12 we report the $\mathrm{H}_{2}$ desorption data pertinent to fully activated $\mathrm{MgH}_{2}$ samples with Fe-Zr mixed additive [18]. For comparison in Figure 13 we present the $\mathrm{H}_{2}$ desorption data at the representative 


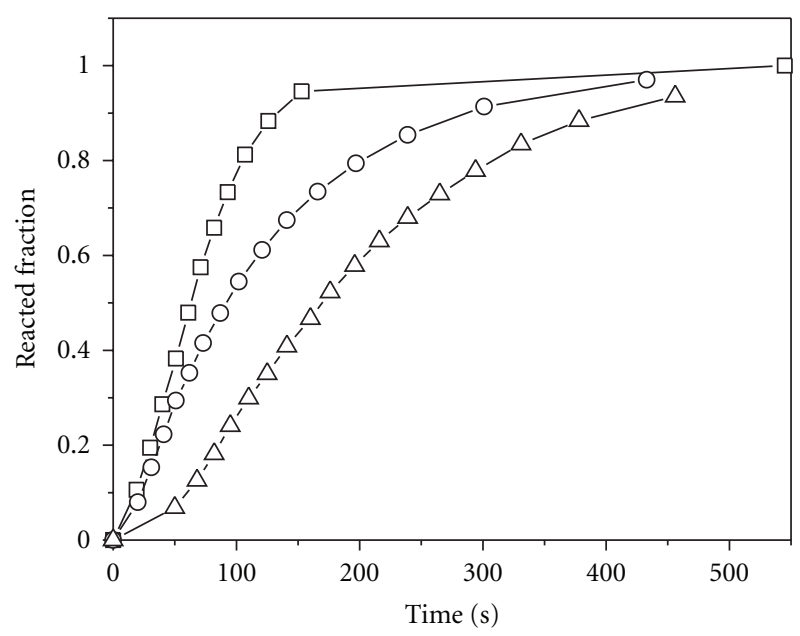

Figure 13: Dehydrogenated fraction versus time at $623 \mathrm{~K}$ of $\mathrm{MgH}_{2}$ sample with $\mathrm{Zr}(\triangle)$ and $\mathrm{Fe}(\bigcirc)$ single additive and mixed $\mathrm{Fe}-\mathrm{Zr}$ additives $(\square)$. The lines are only guide for the eyes.

temperature of $623 \mathrm{~K}$ pertinent to the $\mathrm{MgH}_{2}$ samples with single catalyst: symbols $(\triangle)$ for $\mathrm{Zr}$, symbols $(\bigcirc)$ for Fe. Symbols $(\square)$ are pertinent to the sample with Fe-Zr mixed additives.

In Table 3 we report the kinetic parameters pertinent to samples containing the mixed additives and, as reference, those pertinent to samples with a single additive and to pure $\mathrm{MgH}_{2}$. We note that in presence of mixed additives the hydride to metal phase transition obeys a nucleationand-growth mechanism while in presence of a single catalyst ( 5 at.\% $\mathrm{Fe}$ or 5 at.\% $\mathrm{Nb}$ ) the phase transformation has diffusive character as shown by the different values of the reaction order $n$ and of activation energy $E_{a}$. The most important result is the fact that the mixed additives induce faster desorption kinetic as compared to pure $\mathrm{MgH}_{2}$ and to $\mathrm{MgH}_{2}$ with $\mathrm{Fe}$ or $\mathrm{Nb}$ as single additive as shown by the $\tau_{1 / 2}$ parameter. Table 3 also indicates that the hydride decomposition kinetic with mixed additives is very similar to that of the sample with 1 at.\% $\mathrm{Nb}$ reported in Section 2: the order of reaction is the same, and the activation energy values are very similar. The much better catalytic effect of the mixed additives is related to the impressive increase of preexponential factor $(A)$ growing from $\sim 10^{4}$ to $\sim 10^{8} \mathrm{sec}^{-1}$. We remark that the improved kinetics compared to that of the sample with single Fe or $\mathrm{Zr}$ additive cannot be attributed to the larger additive content because there is a saturation effect in the desorption catalysis with additive contents of $\sim 2$ at.\% [12].

In Figure 14 we present the XRD spectrum of a fully activated sample after $\mathrm{H}_{2}$ desorption that provides information on the physical state of the $\mathrm{Fe}$ and $\mathrm{Zr}$ additives. In the spectrum we observe reflection peaks pertinent to $\mathrm{Mg}$ and the (110), (200), and (211) Bragg reflections of the $\alpha$ Fe phase but no XRD peak attributable to Zr nor to any $\mathrm{Fe}-\mathrm{Zr}$ phase. Because $\mathrm{Zr}$ and $\mathrm{Fe}$ as single additive cannot produce the fast desorption kinetics shown in Figure 12, we may suppose that the improved catalytic effect of the

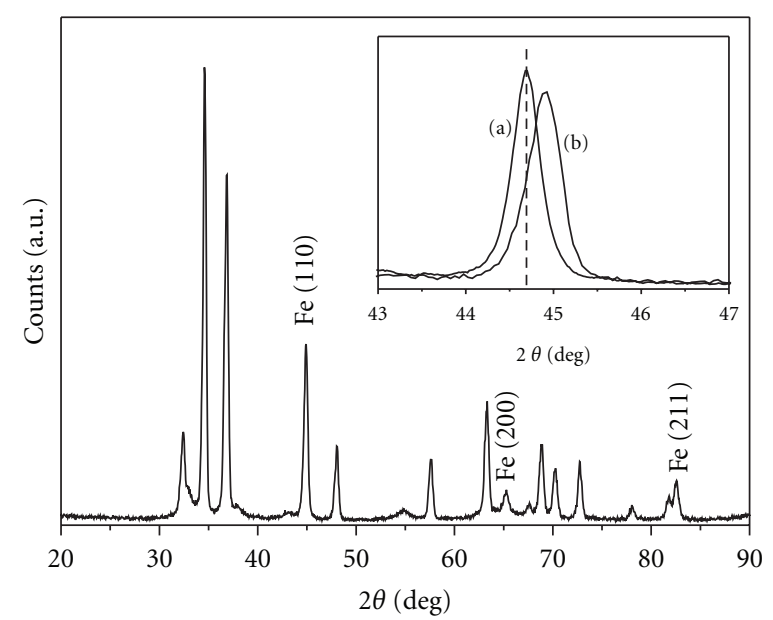

FIGURE 14: XRD spectra pertinent to Mg samples with mixed Fe- $\mathrm{Zr}$ additives (completely activated) after $\mathrm{H}_{2}$ desorption: in the figure only the Fe reflection peaks are labelled and all others peaks are pertinent to h-Mg reflections. In the inset we present the Fe (110) reflection peak pertinent to a sample with only the Fe additive, line (a), and to a sample with mixed Fe-Zr additives, line (b). The thick line is the reference position of the Fe (110) peak [ICDD 06-0696].

mixed additives has two causes: (i) aggregation of Fe into nanoclusters and (ii) atomic dispersion of $\mathrm{Zr}$ (that could also form aggregates but consisting on few atoms). We remark that the second effect has permanent character because, contrarily to the samples with single additive, no evidence of $\mathrm{Zr}$ clustering is observed also after repeated $\mathrm{H}_{2}$ sorption cycles.

By using the Williamson-Hall method [30] the size of the $\alpha$-Fe crystallites was determined to be lower than $20 \mathrm{~nm}$. We can also evaluate a low microstrain value of $\varepsilon \sim 6 \times 10^{-4}$ not observed in the Mg sample with single Fe additive. The intensity ratio of these diffraction peaks indicates that the $\alpha$-Fe nanoclusters have a random distribution in the $\mathrm{Mg}$ matrix. The $\alpha$-Fe clusters size is lower than in Mg samples with single Fe additive, $\sim 30 \mathrm{~nm}$, as evaluated by the BraggBrentano analysis of the (110) reflection peak presented in the inset of Figure 14, line (a) (this is the only $\alpha$-Fe reflection in the XRD spectrum). Both samples have the same Fe content, $\sim 5$ at.\%, and assuming that all Fe atoms form precipitates, we conclude that the sample with mixed additives presents a higher Fe cluster density.

In the $\mathrm{Mg}$ sample with $\mathrm{Zr}$ as single additive, after segregation upon diffusion, $\mathrm{Zr}$ atoms aggregate forming clusters [13]. In the sample with mixed additives these $\mathrm{Zr}$ clusters are not observed: the larger Fe mobility suggests that a possible mechanism impeding the $\mathrm{Zr}$ aggregation is the Fe clustering in the disposable nucleation centres which anticipates the $\mathrm{Zr}$ precipitation. The lower size of the Fe clusters in the Mg sample with mixed additives can be explained by a larger density of available nucleation sites as compared to that in the $\mathrm{Mg}$ sample with single $\mathrm{Fe}$ additive: reasonably, the $\mathrm{Zr}$ few-atom aggregates may constitute precipitation centres for $\mathrm{Fe}$ atoms. 
TABLe 3: Evaluated values of the half-reaction time $\left(\tau_{1 / 2}\right)$ at $T=623 \mathrm{~K}$, order of reaction $(n)$, activation energy $\left(E_{a}\right)$, and pre-exponential factor $(A)$ of pure and TM-doped (TM: $\mathrm{Nb}, \mathrm{Fe}$, and $\mathrm{Zr}+\mathrm{Fe}) \mathrm{MgH}_{2}$ samples.

\begin{tabular}{lcccc}
\hline Sample & $\tau_{1 / 2}(\mathrm{~s})$ & $n$ & $E_{a}\left(\mathrm{~kJ} \mathrm{~mol}^{-1} \mathrm{H}\right)$ & \\
\hline Pure $\mathrm{Mg}$ & $3250 \pm 50$ & 4 & $141 \pm 5$ & \\
$\mathrm{Mg}+5$ at. $\% \mathrm{Nb}$ & $110 \pm 10$ & 1 & $51 \pm 5$ & $\sim 10^{8}$ \\
$\mathrm{Mg}+1$ at. $\% \mathrm{Nb}$ & $290 \pm 10$ & 1.5 & $78 \pm 5$ & $\sim 10^{2}$ \\
$\mathrm{Mg}+5$ at. $\% \mathrm{Fe}$ & $100 \pm 10$ & 1 & $51 \pm 5$ & $\sim 10^{4}$ \\
$\mathrm{Mg}+(\mathrm{Fe}-\mathrm{Zr})$ & $70 \pm 10$ & 1.5 & $94 \pm 5$ & $\sim 10^{2}$ \\
\hline
\end{tabular}

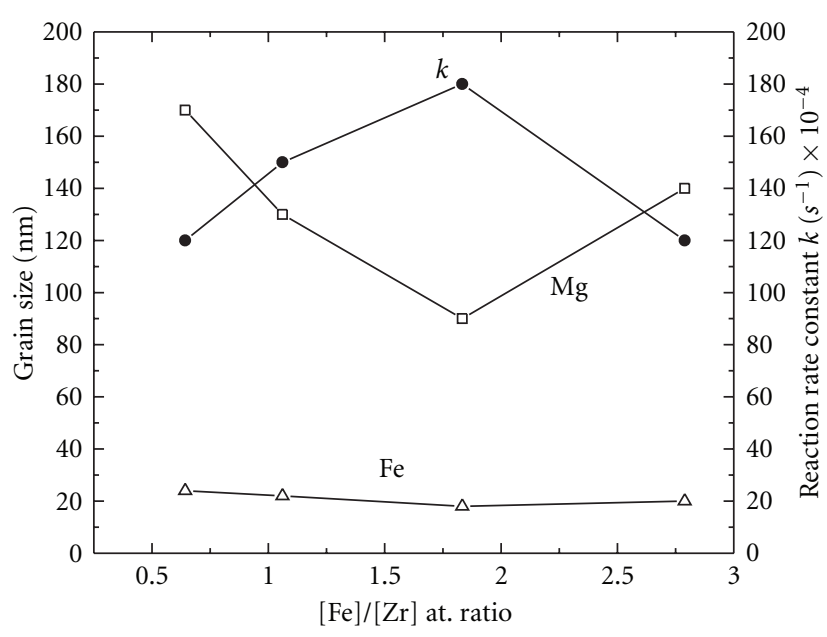

Figure 15: Fe cluster size (triangles), Mg grain size (squares) and desorption rate constant (circles) at different $[\mathrm{Fe}] /[\mathrm{Zr}]$ atomic ratios. The lines are only a guide for the eye.

To gain a deeper understanding on the kinetic processes in presence of mixed additives and to determine which is the optimum Fe and $\mathrm{Zr}$ atomic concentrations, we have prepared samples with fixed metal content, about 7 at.\%, by changing the $[\mathrm{Fe}] /[\mathrm{Zr}]$ atomic ratio [31]. In Figure 15 we summarize the results by showing the size of the Fe nanoclusters, the $\mathrm{Mg}$ grain size, and the desorption rate constant $k(T=623 \mathrm{~K})$ as function of the $[\mathrm{Fe}] /[\mathrm{Zr}]$ ratio. From Figure 15 we observe that (i) the $\mathrm{H}_{2}$ desorption rate constant attains its maximum value when the $[\mathrm{Fe}] /[\mathrm{Zr}]$ atomic ratio is $\sim 1$, (ii) Fe forms nanoclusters with $20 \mathrm{~nm}$ grain size independently on the $[\mathrm{Fe}] /[\mathrm{Zr}]$ atomic ratio, (iii) at $[\mathrm{Fe}] /[\mathrm{Zr}] \sim 1.8$ the $\mathrm{Mg}$ grain size attains its minimum value of about $100 \mathrm{~nm}$, and (iv) there is not evidence of $\mathrm{Zr}$ atoms aggregates.

To explain the previous results, we suggest that the synergetic effect of the mixed $\mathrm{Fe}$ and $\mathrm{Zr}$ additives consists of (i) Fe aggregation forming nanosized clusters that act as $\mathrm{Mg}$ nucleation centers and promote the formation of interconnected $\mathrm{Mg}$ domains for fast $\mathrm{H}$ diffusion and (ii) $\mathrm{Zr}$ atoms playing most probably a role by favoring and stabilizing the aggregation of the Fe additive and as $\mathrm{Mg}$ grain refiner by limiting $\mathrm{Mg}$ grain growth [32]: grain refinement certainly contributes to increase kinetic favoring diffusion through grain boundaries.

In the future it would be interesting to investigate the possible existence of correlation effects on diffusion when different dopants are moving and clustering occurs as observed in [33].

\section{Conclusions}

We have studied the hydrogen desorption kinetics of TMdoped $\mathrm{MgH}_{2}$ samples to analyse the catalytic role of TM atoms and nanoparticles dispersed into the magnesium hydride matrix. We observed that (i) TMs are able to enhance hydrogen desorption also at very low concentration $(0.06$ at.\%) which means that they are atomically dispersed or form a few-atom aggregates, (ii) TM-doped samples show stable desorption properties after a number of $\mathrm{H}_{2}$ sorption cycles when TM nanoclusters are formed with radius on the order of 10-20 nm, and (iii) mixed TM (in the present case Fe and $\mathrm{Zr}$ ) can further enhance the desorption kinetics as compared to the single additive.

The improved $\mathrm{H}_{2}$ desorption properties of the single TM additive are explained by the presence of interfaces between the $\mathrm{MgH}_{2}$ and the TM nanoclusters acting as heterogeneous nucleation sites and promoting the formation of fast diffusion channels for $\mathrm{H}$ migrating atoms. In our case mixed $\mathrm{TM}(\mathrm{Fe}-\mathrm{Zr}$ ) additive in the $\mathrm{Mg}$ matrix optimizes the distribution and size of TM nanoclusters contained inside the $\mathrm{MgH}_{2}$ matrix.

\section{PACS}

64.70.K-: Solid-solid transitions

61.46.+w: Nanoscale materials: clusters, nanoparticles, nanotubes and nanocrystals

61.05.C-: X-ray diffraction and scattering

68.37.Lp: Transmission electron microscopy (TEM)

68.43.Nr: Desorption kinetics

68.43.Vx Thermal desorption

81.05.-t: Specific materials: fabrication, treatment, testing, and analysis

82.65.+r: Surface and interface chemistry; heterogeneous catalysis at surfaces

84.60.Ve: Energy storage systems, including capacitor banks.

\section{Acknowledgments}

The authors thank Cristina Armellini for XRD analysis, Chiara Maurizio for EXAFS analysis, Paolo Mengucci for TEM analysis, Paolo Mazzoldi and Cinzia Sada for SIMS analysis, Romina Belli for EDS analysis, and Ashwin Kale 
for support on $\mathrm{Mg}$ samples preparation with mixed $\mathrm{TM}$ additives. The research activity is financially supported by the Hydrogen-FISR Italian Project.

\section{References}

[1] R. Gonzalez, Y. Chen, and K. L. Tsang, "Diffusion of deuterium and hydrogen in doped and undoped MgO crystals," Physical Review B, vol. 26, no. 8, pp. 4637-4645, 1982.

[2] O. Friedrichs, J. C. Sánchez-López, C. López-Cartes et al., "Chemical and microstructural study of the oxygen passivation behaviour of nanocrystalline $\mathrm{Mg}$ and $\mathrm{MgH} 2$," Applied Surface Science, vol. 252, no. 6, pp. 2334-2345, 2006.

[3] G. Friedlmeier and M. Groll, "Experimental analysis and modelling of the hydriding kinetics of $\mathrm{Ni}$-doped and pure Mg," Journal of Alloys and Compounds, vol. 253-254, pp. 550$555,1997$.

[4] A. Zaluska, L. Zaluski, and J.O. Ström-Olsen, "Structure, catalysis and atomic reactions on the nano-scale: a systematic approach to metal hydrides for hydrogen storage," Applied Physics A, vol. 72, no. 2, pp. 157-165, 2001.

[5] G. Barkhordarian, T. Klassen, and R. Bormann, "Catalytic mechanism of transition-metal compounds on $\mathrm{Mg}$ hydrogen sorption reaction," Journal of Physical Chemistry B, vol. 110, no. 22, pp. 11020-11024, 2006.

[6] J. F. Pelletier, J. Huot, M. Sutton et al., "Hydrogen desorption mechanism in MgH2-Nb nanocomposites," Physical Review B, vol. 63, no. 5, Article ID 052103, pp. 1-4, 2001.

[7] H. G. Schimmel, J. Huot, L. C. Chapon, F. D. Tichelaar, and F. M. Mulder, "Hydrogen cycling of niobium and vanadium catalyzed nanostructured magnesium," Journal of the American Chemical Society, vol. 127, no. 41, pp. 1434814354, 2005.

[8] O. Friedrichs, J. C. Sánchez-López, C. López-Cartes, T. Klassen, R. Bormann, and A. Fernández, " $\mathrm{Nb}_{2} \mathrm{O}_{5}$ "pathway effect" on hydrogen sorption in Mg," Journal of Physical Chemistry B, vol. 110, no. 15, pp. 7845-7850, 2006.

[9] N. Bazzanella, R. Checchetto, and A. Miotello, "Catalytic effect on hydrogen desorption in Nb-doped microcrystalline MgH2," Applied Physics Letters, vol. 85, no. 22, pp. 5212-5214, 2004.

[10] R. Checchetto, N. Bazzanella, A. Miotello, and P. Mengucci, "Deuterium storage in Mg-Nb films," Journal of Alloys and Compounds, vol. 404-406, pp. 461-464, 2005.

[11] R. Checchetto, N. Bazzanella, A. Miotello et al., "Nb clusters formation in Nb-doped magnesium hydride," Applied Physics Letters, vol. 87, no. 6, Article ID 061904, 3 pages, 2005.

[12] N. Bazzanella, R. Checchetto, A. Miotello, C. Sada, P. Mazzoldi, and P. Mengucci, "Hydrogen kinetics in magnesium hydride: on different catalytic effects of niobium," Applied Physics Letters, vol. 89, no. 1, Article ID 014101, 3 pages, 2006.

[13] R. Checchetto, N. Bazzanella, A. Miotello, and P. Mengucci, "Catalytic properties on the hydrogen desorption process of metallic additives dispersed in the $\mathrm{MgH} 2$ matrix," Journal of Alloys and Compounds, vol. 446-447, pp. 58-62, 2007.

[14] N. Bazzanella, R. Checchetto, and A. Miotello, "Catalytic effect of mixed $\mathrm{Zr}$-Fe additives on the hydrogen desorption kinetics of $\mathrm{MgH}_{2}$," Applied Physics Letters, vol. 92, no. 5, Article ID 051910, 2008.

[15] R. Checchetto, N. Bazzanella, A. Miotello, R. S. Brusa, A. Zecca, and A. Mengucci, "Deuterium storage in nanocrystalline magnesium thin films," Journal of Applied Physics, vol. 95, no. 4, pp. 1989-1995, 2004.
[16] M. A. Pick, J. W. Davenport, M. Strongin, and G. J. Dienes, "Enhancement of hydrogen uptake rates for $\mathrm{Nb}$ and $\mathrm{Ta}$ by thin surface overlayers," Physical Review Letters, vol. 43, no. 4, pp. 286-289, 1979.

[17] R. Checchetto, G. Trettel, and A. Miotello, "Sievert-type apparatus for the study of hydrogen storage in solids," Measurement Science and Technology, vol. 15, no. 1, pp. 127$130,2004$.

[18] J. W. Christian, The Theory of Transformations in Metals and Alloys. Part I, Pergamon, Oxford, UK, 2002.

[19] J. Renner and H. J. Grabke, "Determination of diffusion coefficients in the hydriding of alloys," Zeitschrift fuer Metallkunde, vol. 69, no. 10, pp. 639-642, 1978.

[20] G. Liang, J. Huot, S. Boily, A. Van Neste, and R. Schulz, "Catalytic effect of transition metals on hydrogen sorption in nanocrystalline ball milled $\mathrm{MgH}_{2}-\mathrm{Tm}(\mathrm{Tm}=\mathrm{Ti}, \mathrm{V}, \mathrm{Mn}, \mathrm{Fe}$ and Ni) systems," Journal of Alloys and Compounds, vol. 292, no. 1-2, pp. 247-252, 1999.

[21] G. Barkhordarian, T. Klassen, and R. Bormann, "Kinetic investigation of the effect of milling time on the hydrogen sorption reaction of magnesium catalyzed with different $\mathrm{Nb}_{2} \mathrm{O}_{2}$ contents," Journal of Alloys and Compounds, vol. 407, no. 1-2, pp. 249-255, 2006.

[22] J. F. Fernández and C. R. Sánchez, "Rate determining step in the absorption and desorption of hydrogen by magnesium," Journal of Alloys and Compounds, vol. 340, no. 1-2, pp. 189198, 2002.

[23] A. A. Nayeb-Hashemy and J. B. Clark, Phase Diagrams of Binary Magnesium Alloys, ASM International, Metal Park, Ohio, USA, 1988.

[24] G. Alefeld and J. Völkl, Hydrogen in Metals, Springer, Berlin, Germany, 1978.

[25] M. A. Pick and R. Bausch, "The determination of the forcedipole tensor of hydrogen in niobium," Journal of Physics F, vol. 6, no. 10, article no. 008, pp. 1751-1763, 1976.

[26] D. A. Porter and K. E. Easterling, Phase Transformation in Metals and Alloys, Chapmann \& Hall, London, UK, 1992.

[27] D. Turnbull, Solid State Physics, vol. 3, Academic Press, New York, NY, USA, 1956.

[28] F. D. Manchester, Phase Diagrams of Binary Hydrogen Alloys, ASM International, Materials Park, Ohio, USA, 2000.

[29] O. Friedrichs, D. Martínez-Martínez, G. Guilera, J. C. S. López, and A. Fernández, "In situ energy-dispersive XAS and XRD study of the superior hydrogen storage system $\mathrm{MgH}_{2} / \mathrm{Nb}_{2} \mathrm{O}_{5}$," Journal of Physical Chemistry C, vol. 111, no. 28, pp. 1070010706, 2007.

[30] G. K. Williamson and W. H. Hall, "X-ray line broadening from filed aluminium and wolfram," Acta Metallurgica, vol. 1, no. 1, pp. 22-31, 1953.

[31] A. Kale, N. Bazzanella, R. Checchetto, and A. Miotello, "Synergy on catalytic effect of $\mathrm{Fe}-\mathrm{Zr}$ additives mixed in different proportions on the hydrogen desorption from $\mathrm{MgH}_{2}$," Applied Physics Letters, vol. 94, no. 20, Article ID 204103, 2 pages, 2009.

[32] E. F. Emley, Principles of Magnesium Technology, Pergamon, Oxford, UK, 1966.

[33] A. Miotello, G. De Marchi, G. Mattei, P. Mazzoldi, and C. Sada, "Clustering of gold atoms in ion-implanted silica after thermal annealing in different atmospheres," Physical Review B, vol. 63, no. 7, Article ID 075409, 7 pages, 2001. 

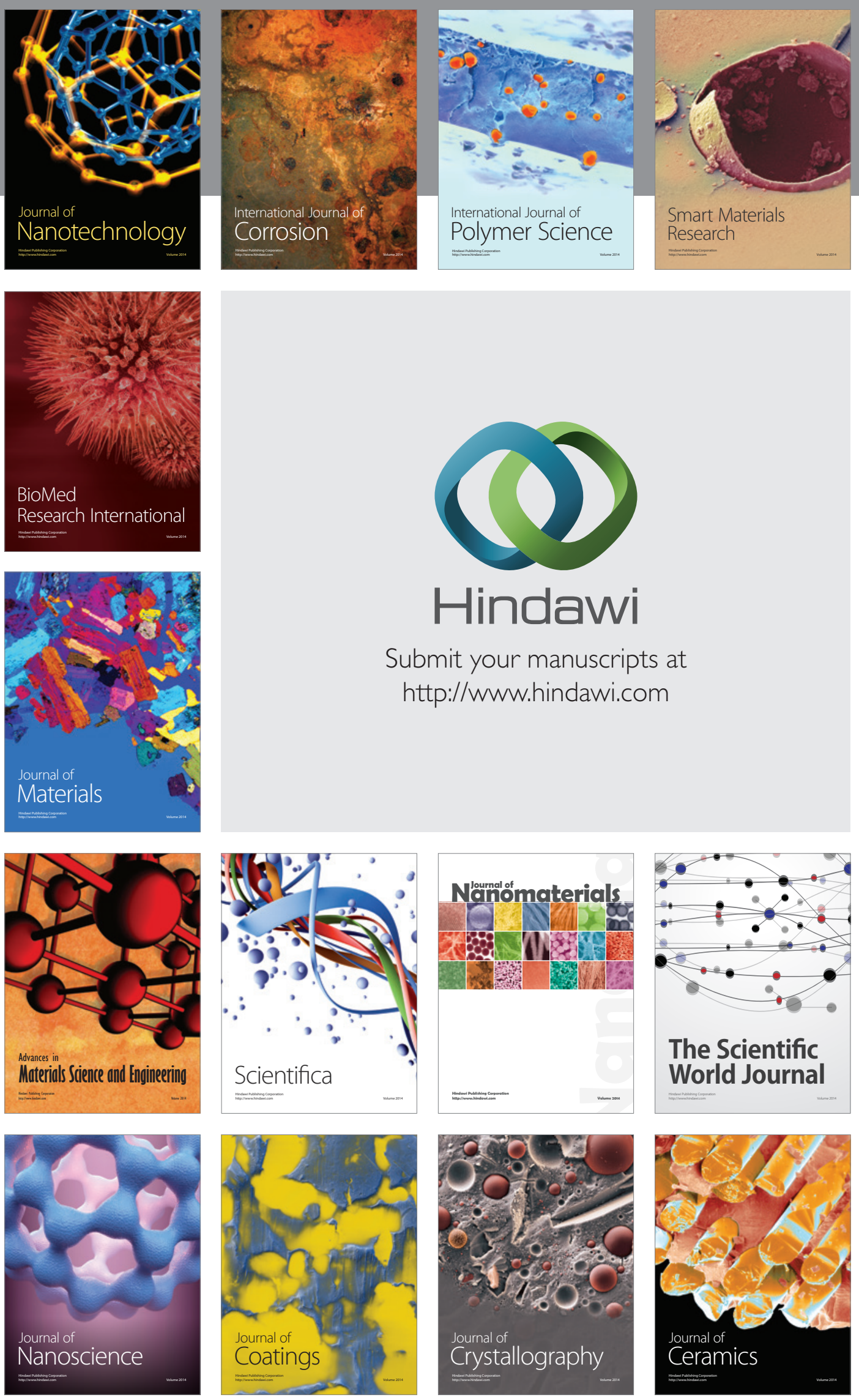

The Scientific World Journal

Submit your manuscripts at

http://www.hindawi.com

\section{World Journal}

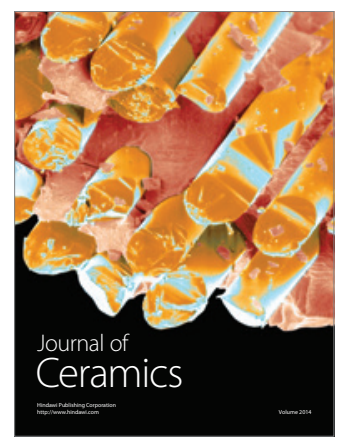

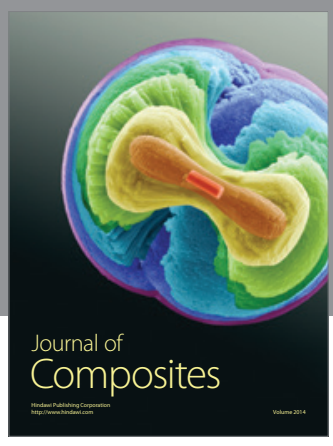
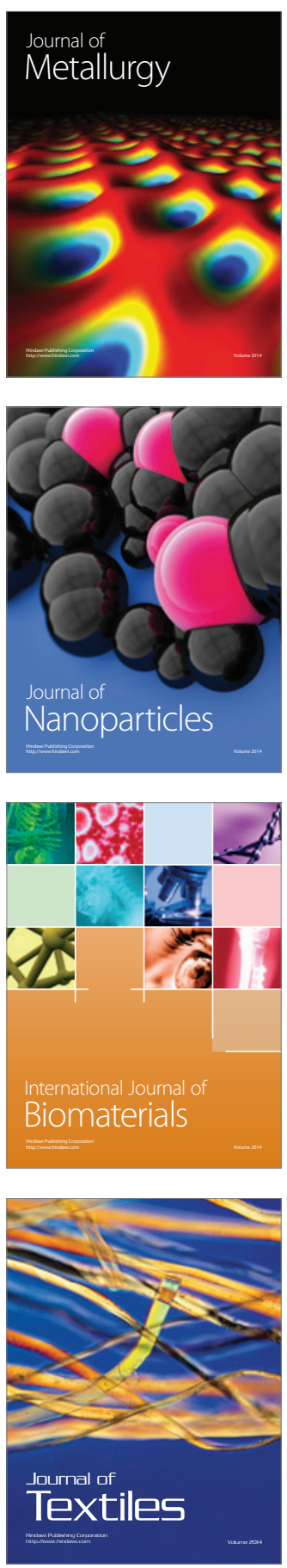